\title{
Misleading linkage results in an NF2 presymptomatic test owing to mosaicism
}

\author{
E K Bijlsma, A J Wallace, D G R Evans
}

\begin{abstract}
A two generation family with neurofibromatosis type 2 (NF2) is presented in which a family member requested presymptomatic molecular diagnosis. Since the consultand's mother had clinically well defined NF2, he was quoted to be at $50 \%$ risk of carrying an NF2 mutation. Mutation screening in the mother did not show the causative mutation and, consequently, presymptomatic testing was based on linkage analysis. This showed that the consultand carried the high risk chromosome 22. Subsequent mutation screening of his clinically affected sister showed a nonsense mutation, $R 262 X$ in exon 8 of the NF2 gene. The mother turned out to be a mosaic for $R 262 X$; the son had not inherited the mutation.

Mosaicism may be a common mechanism in NF2 and other autosomal dominant diseases with a high new mutation rate. This may be one explanation for a difference in expression in generations. Caution has to be exercised when giving results based on linkage tests which imply a very high risk to people in the second generation.

(F Med Genet 1997;34:934-936)
\end{abstract}

Keywords: NF2; mosaicism; linkage analysis; misleading result

Medical Genetics, St

Mary's Hospital, Manchester M13 0JH, UK

A J Wallace

D G R Evans

Correspondence to: Dr Evans.

Received 14 February 1997 Revised version accepted for publication 25 April 1997
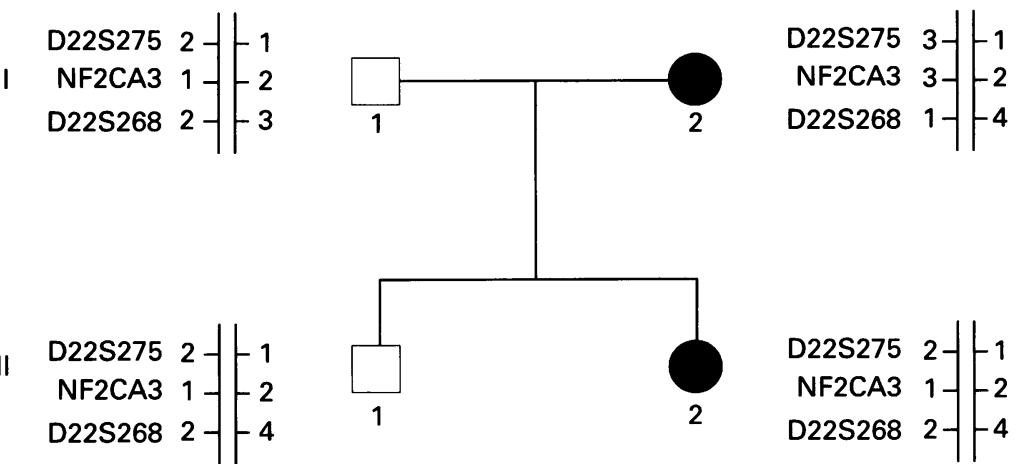

Figure 1 Pedigree and haplotypes around the NF2 gene. II. 1 and II.2 inherited the same haplotype from I.2 for all three loci. been performed in suitable families to predict the carrier status of at risk family members. ${ }^{6}$ Since the NF2 gene was characterised in $1993,{ }^{78}$ it is possible to screen for mutations in patients and offer presymptomatic testing to those at risk when a causative mutation has been found. However, detection rate for mutations is at best $50 \%,{ }^{10}$ and therefore in many families predictive testing is still based on linkage analysis.

Here we describe a family in which mosaicism was the cause of a misleading result in NF2 presymptomatic testing by linkage analysis. The proband (I.2) (fig 1) was a 46 year old woman with seven healthy sibs; her father died at the age of 47 from cardiac and hepatic disease and her mother was well at the age of 68 years. She showed the first signs of NF2 at the age of 23 when she developed grand $\mathrm{mal}$ epileptic attacks and at the age of 25 she presented with left sided hemiparesis and a parasagittal meningioma was detected on CT scan and surgically removed. She has since developed classical NF2 with bilateral vestibular schwannoma, multiple meningiomas, and spinal schwannomas.

Her son (II.1) showed no clinical manifestations on physical and neurological examination. An MRI of the cranium and spine showed no evidence for intracranial or spinal tumours. Audiology and brain stem auditory

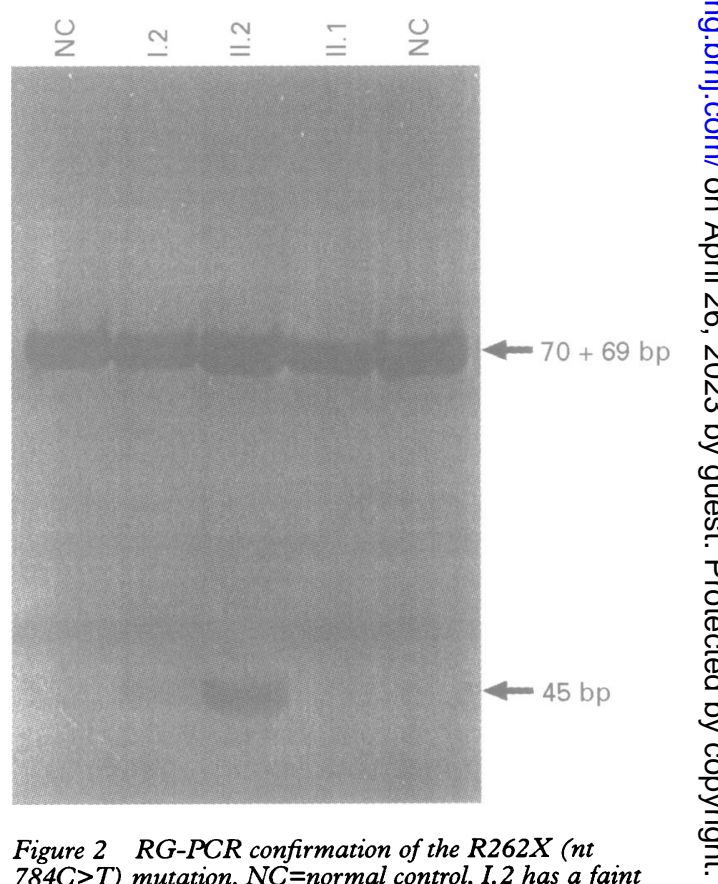
$784 C>T$ ) mutation. NC=normal control. $I .2$ has a faint but discernible $45 \mathrm{bp}$ band indicating the presence of $R 262 X$. 
evoked reflexes (BAER) were both normal. During follow up there was no change.

Her daughter (II.2) had very poor balance and diminished corneal reflexes bilaterally on physical and neurological examination. Audiology showed bilateral sensorineural hearing loss, more marked on the right. BAER results were in accordance with retrocochlear pathology. MRI showed bilateral vestibular schwannomas as well as multiple small cranial tumours (meningiomas and schwannomas) and several small spinal schwannomas.

Initial mutation analysis in the mother using a combined SSCP/heteroduplex analysis approach $^{11}$ did not detect a mutation in the NF2 gene. However, this was a two generation

NC
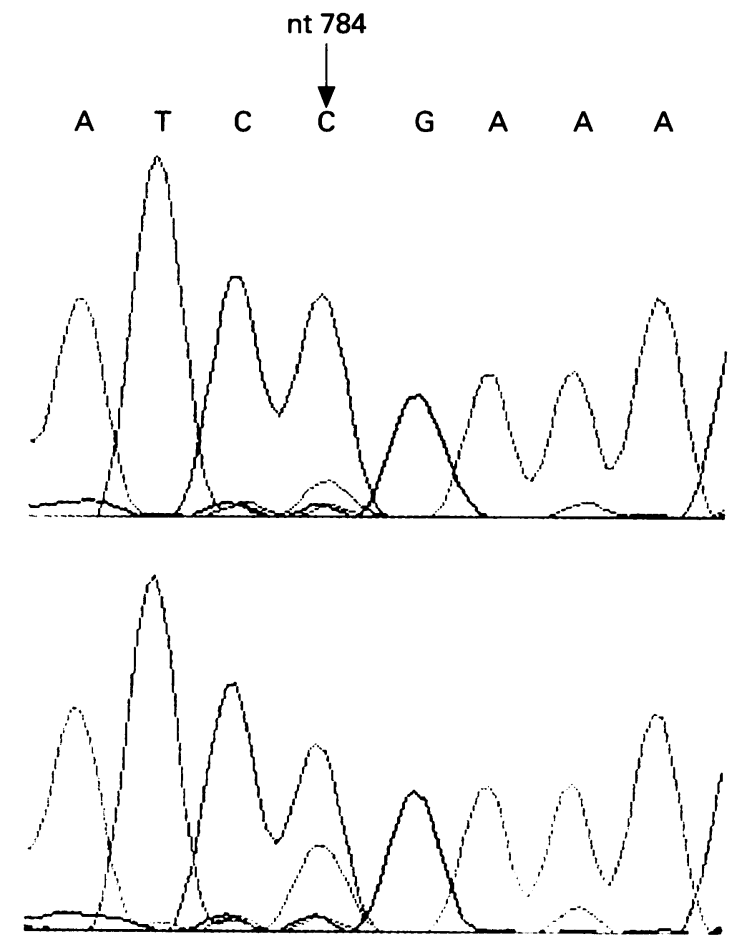

II. 2

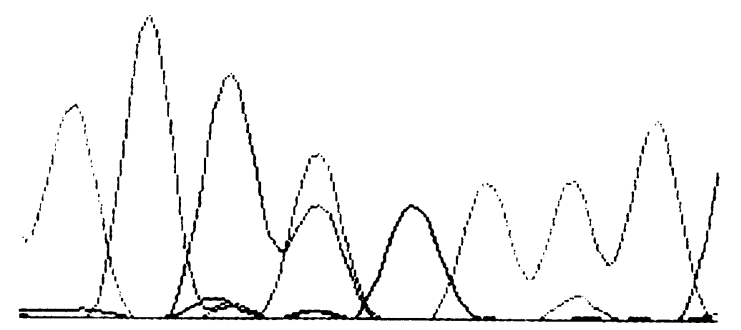

II.1

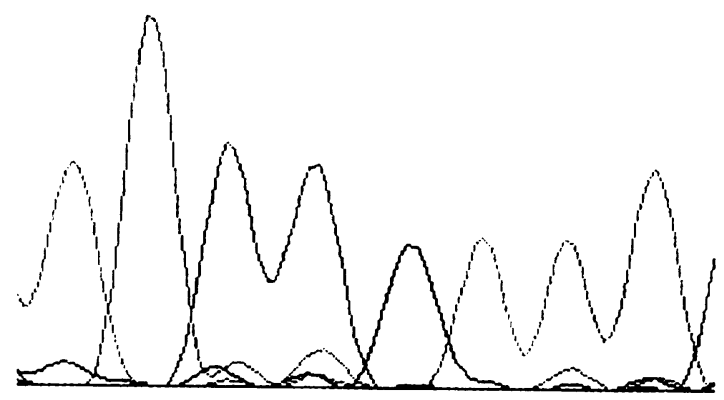

Figure 3 Dye primer sequencing of the $R 262 X$ ( $n t 784 C>T$ ) mutation. NC=normal control. II. 2 is clearly heterozygous whereas II. 1 is identical to the normal control. I. 2 clearly has 784 T but the peak height is substantially lower than that in II. 2 whereas the $784 C$ peak shows a reciprocal pattern. family, so linkage analysis was potentially able to provide presymptomatic testing. Subsequent testing with microsatellite markers showed that the family was informative with NF2CA3, a polymorphic marker located within the NF2 gene, ${ }^{12}$ as well as with the flanking extragenic markers D22S275 ${ }^{13}$ and D22S268. ${ }^{14}$ Therefore, it was decided to perform presymptomatic testing in II. 1 based on linkage analysis. The results for all three markers indicated that II.1 had inherited the same maternal chromosome 22 as his sister, giving a risk of $>99.9 \%$ that he would be affected (fig 1). Consequently, he was counselled as high risk and was monitored accordingly.

Some doubt still existed over the result, given the complete absence of tumours compared to his sister, and therefore mutation screening of the NF2 gene in II.1 was undertaken. This identified an SSCP shift in exon 8 of the NF2 gene which was subsequently sequenced as a nonsense mutation, R262X (nt 784C $>\mathrm{T}$ ) (data not shown). In order to confirm the presence of R262X in II.2, and to facilitate screening of other members of the same family, a restriction generating (RG) primer was designed to engineer the creation of a novel DdeI site in the presence of $784 \mathrm{C}>\mathrm{T}$. The sequence of the R262X RG PCR primer (R262X-RGR) was 5'-CCTTGTCACTGT ACGAGATGTCTC-3' and this was used in conjunction with the exon 8 forward primer described by Mérel et al, ${ }^{10}$ (NF2-8F) 5'CCACAGAATAAAAAGGGCAC-3'. The predicted fragment sizes were 70 and 69 bp for the normal allele and 70,45 , and 24 bp for $784 \mathrm{C}>\mathrm{T}$. In practice the $24 \mathrm{bp}$ fragment could not be seen since it was obscured by the residual primers from the PCR reaction. II.2 showed the expected novel $45 \mathrm{bp}$ fragment using the RG-PCR assay, whereas these were clearly not present in II.1 (fig 2). Interestingly I. 2 showed a faint $45 \mathrm{bp}$ signal indicating that the stoichiometry of the normal versus mutant alleles was not the $1: 1$ ratio present in II.2.

Comparative dye primer cycle sequencing of exon 8 of I.2, II.1, and II.2 was then undertaken, to confirm the findings from the RG-PCR test and provide an estimate of the degree of mosaicism in I.2 (fig 3). II.1 showed the same pattern at residue 784 as a normal control, confirming that he had not inherited R262X. II. 2 was clearly heterozygous for $784 \mathrm{C}>\mathrm{T}$ although the $\mathrm{C}$ and $\mathrm{T}$ peaks were not of equal height. I. 2 clearly showed the presence of a T peak at 784 although its height was patently lower than that in II.2. To give a quantitative estimate of the degree of mosaicism in I.2, the heights of the $C$ and $T$ peaks at nt 784 were measured in the normal control and in II.2. They were then normalised against the height of the neighbouring $C$ peak at nt 783 . These measurements set the $100 \%$ to $50 \%$ values for $784 \mathrm{C}$ and $0 \%$ to $50 \%$ values for $784 \mathrm{~T}$. The peak heights of $784 \mathrm{C}$ and $784 \mathrm{~T}$ in I. 2 were then interpolated on a graph obtained by joining the points derived from the normal control and II.2. This gave an estimated contribution of $81.3 \%$ for $784 \mathrm{C}$ and $18.7 \%$ for $784 \mathrm{~T}$ equat- 
ing to $\mathrm{I} .2$ carrying the $784 \mathrm{C}>\mathrm{T}$ mutation in $37.4 \%$ of her lymphocytes.

Clearly mosaicism was the cause of the misleading result in the presymptomatic test by linkage analysis in this family. A similar family study for retinoblastoma has recently been reported by Thonney et al. ${ }^{15}$ Linkage analysis in this family indicated that the presumably mutated intragenic haplotype found in the affected child was shared by the two unaffected sibs. Mutation identification showed that the father of the children was mosaic for a mutation in the RB gene, and that the two sibs were homozygous for the wild type allele. In this family germinal mosaicism was therefore established.

These two cases illustrate that in some families inheritance of an autosomal dominant disease cannot be established by linkage analysis alone. In all de novo cases of an autosomal dominant disease the possible existence of two cell populations has to be taken into account. Subjects who have the classical phenotype of the disease are likely to have a mutation in all their cells. However, subjects who are mildly affected or appear to have segmental disease may be mosaic for a mutation. Similar cases may well occur in FAP (familial adenomatous polyposis coli), von Hippel-Lindau disease, and NF1 and should always be suspected if the parent of a classically affected subject has only one or two manifestations. In NF1 the skin involvement may well be segmental. ${ }^{16}$ However, our case illustrates that even in classically, bilaterally affected subjects mosaicism may occur. It is possible that the neural crest had a higher percentage involvement than other constitutional tissues and this may have connotations for embryological development.

In NF2, only one mosaic patient has previously been reported (patient B in Bourn et $\left.a l^{p}\right)$. He had late onset NF2 with a relatively benign course. It was shown that he had somatic mosaicism for a nonsense mutation in exon 2 of the NF2 gene. Four of his five clinically unaffected children were tested and none of them had the mutation. Recently, the family has been haplotyped. Two children have inherited one paternal chromosome 22 and two have inherited the other (G Evans, unpublished results). Since there are no affected children, it is uncertain whether patient B has germinal mosaicism.

Mosaicism could be a common mechanism in other autosomal dominant diseases with a high mutation rate. ${ }^{9}$ It could also be an expla- nation for apparent anticipation effects and variable expression between the first and second generation. ${ }^{917} 18$ In this family, both mother and daughter had their first signs in their early twenties. At the age of 47 the mother is doing surprisingly well, despite the burden of tumours. It is too early to comment on the course of the disease in her daughter.

In conclusion, caution has to be exercised when giving results of linkage tests which imply a very high risk to people in the second generation.

1 Kanter WR, Eldridge R, Fabricant R, Allen JC, Koerber T. Central neurofibromatosis with bilateral acoustic neuroma: genetic, clinical and biochemical distinctions from peripheral neurofibromatosis. Neurology 1980;30:851-9.

2 Evans DGR, Huson SM, Donnai D, et al. A clinical study of type 2 neurofibromatosis. $Q \mathcal{F}$ Med 1992;84:603-18.

3 Parry DM, Eldridge R, Kaiser-Kupfer MI, Bouzas EA, Pikus A, Patronas N. Neurofibromatosis 2 (NF2): clinical characteristics of 63 affected individuals and clinical evidence for heterogeneity. Am $\mathcal{F}$ Med Genet 1994;52:450-

4 Seizinger BR, Martuza RL, Gusella JF. Loss of genes on chromosome 22 in tumorigenesis of human acoustic chromosome Nature 1986;322:644-7.

5 Rouleau G, Wertelecki W, Haines JL, et al. Genetic linkage analysis of bilateral acoustic neurofibromatosis to a DNA analysis of bilateral acoustic neurofibromatosis to a

6 Ruttledge MH, Narod SA, Dumanski JP, et al. Presymptomatic diagnosis for neurofibromatosis 2 with chromosome 22 markers. Neurology 1993;43:1753-60.

7 Rouleau GA, Mérel P, Lutchman M, et al. Alteration in a new gene encoding a putative membrane-organizing protein causes neuro-fibromatosis type 2 . Nature 1993;363: 515-21.

8 Trofatter JA, MacCollin MM, Rutter JL, et al. A novel moesin-, ezrin-, radixin-like gene is a candidate for the neurofibromatosis 2 tumor suppressor. Cell 1993;72:791800 .

9 Bourn D, Carter SA, Evans DGR, Goodship J, Coakham H, Strachan T. A mutation in the neurofibromatosis type 2 tumor-suppressor gene, giving rise to widely different clini$\mathrm{cal}$ phenotypes in two unrelated individuals. Am $7 \mathrm{Hum}$ Genet 1994;55:69-73.

10 Mérel P, Hoang-Xuan K, Sanson M, et al. Screening for germline mutations in the NF2 gene. Genes Chrom Cancer 1995;12:117-27.

11 Evans DGR, Bourne D, Wallace A, Ramsden RT, Mitchell JD, Strachan T. Diagnostic issues in a family with late onset type 2 neurofibromatosis. $₹$ Med Genet 1995;32:470-4

12 Bourn D, Strachan T. Highly polymorphic dinucleotide repeat at the NF2 gene. Hum Genet 1995;95:712.

13 Weissenbach J, Gyapay G, Dib C, et al. A second generation map of the human genome. Nature 1992;359:794-801.

14 Marineau C, Baron C, Delattre O, et al. Dinucleotide repeat polymorphism at the D22S268 locus. Hum Mol Genet 1993;2:336.

15 Thonney F, Munier F, Balmer A, Heon E, Pescia G, Schorderet DF. Rbl mutation mosaicism in a retinoblastoma family. Am f Hum Genet 1996;59:A84.

16 Huson SM. Neurofibromatosis 1: a clinical and genetic overview. In: Huson SM, Hughes RAC, eds. The neurofibromatoses: a pathogenetic and clinical overview. Chapter 7. London: Chapman \& Hall, 1994:160-203.

17 Gardner WJ, Frazier $\mathrm{CH}$. Bilateral acoustic neurofibromas: a clinical study and field survey of a family of five generations with bilateral deafness in thirty eight members. Arch Neurol Psychiatr 1930;23:266-302.

18 Evans DGR, Huson SM, Donnai D, et al. A genetic study of type 2 neurofibromatosis in the north west of England and the UK. I. Prevalence, mutation rate, fitness, and confirmation of maternal transmission effect on severity. $\mathcal{F}$ Med Genet 1992;29:841-6. 